Journal of Advanced College of Engineering and Management, Vol. 6, 2021

\title{
STUDY ON MECHANICAL PROPERTIES OF TMT BARS MANUFACTURED IN NEPAL
}

\author{
Umesh Yadav ${ }^{1}$, Bhakta BahadurAle ${ }^{2}$ \\ 1,2 Department of Mechanical Engineering, Pulchowk Campus, Institute of Engineering, T.U., Nepal \\ ${ }^{1}$ Email Address: iamumesh47@gmail.com
}

\begin{abstract}
Three grades of deformed steel bar are presently available in Nepal for concrete reinforcement. The deformed bars are graded according to their specified yield strength. These are Fe415, Fe500 and Fe500D. CTD bars of grade more than Fe415 are scarcely available in market. However, TMT bars of Fe500 grade are easily available in market. This study is undertaken to evaluate the variability of the mechanical properties of reinforcing steel granted with NS Mark and to analyze the degree to which these rolling mills satisfy the minimum requirements established by product national standard NS:191. The data obtained from test results are statistically analyzed to evaluate the variability in the mechanical properties of TMT bars. For the tested mechanical properties, the parameters evaluated for each bar size, and grade at confidence level at $95 \%$ are mean, standard deviation, coefficient of variation, minimum, maximum, skewness. The samples were collected from NBSM reference sample store room of FY 2073-74 and FY 2074-75. These samples were from nineteen industries and twenty-two different brands. Total 745 numbers of TMT bars of grade Fe500 and Fe500D were tested at NBSM mechanical testing laboratory. The mechanical properties determined from the tested samples are: mass per meter run, yield stress, tensile stress, percentage elongation, UTS/YS ratio, total elongation at maximum force, and bond value.The tested data and obtained statistics of different mechanical properties for the separate and combined data takes on an important practical significance and may be used in calibrating local specifications and designs.
\end{abstract}

Keywords: TMT bars, Mechanical properties, Nepal Standard (NS), variability in properties

\section{Introduction}

Nepal is situated in a tectonic plate, which is more prone to earthquakes. Thermomechanically treated deformed bars (TMT bars) impart strength and ductility to RCC structure to withstand various kinds of loads impacting a building. These days a lot of focus is given in designing structures that have high earthquake resistance. TMT bars have high fatigue resistance to seismic loads due to its higher UTS/YS ratio. This makes them most suitable for use in earthquake prone areas. Census of Manufacturing Establishment (CME) carried out in the fiscal year 2011/12 by the Central Bureau of Statistics (CBS) has classified Metal industry into three different classes namely a) basic iron and steel, b) structural metal products, and c) forging, pressing and stamping of metal. Iron rod, steel rod, stainless steel, cast iron pipe, corrugated sheet etc. are some of the export items of the industry. The number of basic iron and steel industries in Nepal is 20 with employment of 4,917 persons (CME, 2012/13). The sub-sector output value is estimated to be NPR 31.0 billion and contributes the input value of NPR 27.34 billion with addition of about NPR 3.75 billion. The average installed capacity of the plants in this sub-sector is 113 Tons per Day (TPD) and average production is 63.7 TPD (GIZ/NEEP, 2012).

Nepal has become self-sufficient in iron and steel materials due to increased production from old industries which is expanding capacity and new industries joining the business. Annual demand of iron and steel currently stands at around 2 million tonnes and domestic producers are supplying the required quantity in the market. New investment in the industry is a result of increased development works, boom in the construction of houses and commercial buildings. Iron and steel demand has been increased by 10 percent annually.

Almost 90 percent of raw materials are imported from India. The remaining comes from third countries. Nepal has been importing raw materials and other related materials to manufacture reinforcement bar. The country imported MS steel billet, a major raw material, worth Rs. 459.5 million in the FY 2074/75. 
Houses in the hilly regions were mostly constructed from bricks, mud and wood till a few years ago. However, people in these areas nowadays build houses using concrete and iron bars. Some earthquake affected people have reconstructed their homes with modern construction materials. However, the construction of government buildings, historical monuments and religious structures destroyed or damaged by earthquake is in the process to build up. Similarly, the development of unified housing in the quake affected districts has begun. Hence, the demand for iron and steel bars has increased.

About $10 \%$ of buildings in Nepal are RC buildings. The construction of RC buildings only started after 1980; however the mushrooming number of RC construction was started only after 1990. Even though the RC construction was started in early 1980s, engineered construction was only felt after enforcement of building codes in 2006 and almost $70 \%$ of existing RC buildings are either owner built constructions constructed with the help of contractors following by-laws or constructed as per the mandatory rules of thumbs as suggested by Nepal Building Code (NBC, 1994).

Under the category of material property variations, the variability of the mechanical properties of reinforcing steel affects the performance of reinforced concrete structures. In Nepal, these properties have minimum requirements, as detailed by (NS:191-2046, 2069).

This study is undertaken to evaluate the variability of the mechanical properties of reinforcing steel produced throughout the Nepal and to analyze the degree to which manufacturers satisfy the minimum requirements established by product national standard (NS:191-2046, 2069). This study is conducted by collecting samples of Grade Fe 500 and Fe500DTMT bars, testing these samples in mechanical testing laboratory, and statistically analyzing the test data obtained from test results. NS standards establish minimum criteria for the mechanical properties of all reinforcing steel produced in Nepal. However, they do not set maximum limits nor do they address instances where properties may significantly exceed the standards. With the exceptions of structures designed for seismic applications, designers use the minimum values in design without considering the true strength of the reinforced steel. This may be of concern because member behavior can differ from the planned response if material properties are significantly higher than those used in the design.

The mechanical properties of reinforcing steel are controllable in the manufacturing process, but variations between manufacturers and between heats for the same manufacturers do exist. Results may be influenced by several factors including but not limited to the rate of loading, bar cross-sectional area, and variation in the chemical composition of steel. All reinforcing steel manufacturers must perform tests on their products to verify that they meet the (NS:191-2046, 2069) Standard. These tests measured mass per meter run, yield strength, tensile strength, percentage elongation, bond value, bend test, rebend test and total elongation at maximum force. Chemical analysis of the billet is also important parameter to comply as per product standard.

\section{Literature Review}

The variability of the mechanical properties of reinforcing steel is studied by several researchers. In 1972, the National Research Council (NRC) of Canada published the results of a study analyzing the mechanical properties of reinforcement steel (Allen, 1972). Two data samples were used, one consisting of 132 bars from Canadian manufacturing plant and the other consisting of tests by the NRC on 102 bars obtained from five separate heats. The NRC tests, performed using greater control than those specified by ASTM or CSA, provided information about the variations along a bar and from one bar to another within a heat. The manufacturing plant data provided information on the overall variability of reinforcing steel from one manufacturer. The results showed that the coefficient of variation increased as one move from one bar to a group of bars from the same heat and then to the entire plant. Additionally, a significant difference in the stress-strain curve $\mathrm{s}$ was found to exist between No. 3 and larger bars. The curves for No. 3 bars had no yield plateau, while that of the larger bars did. 
This difference was explained based on the possibility that the No. 3 bars had undergone cold working due to their smaller size.

Several properties were measured under two loading conditions: static and dynamic (standard). Allen (1972) felt that the static loading condition better reflected actual loading conditions, and he concluded that subtracting an empirically derived value from mill test results would provide the static yield stresses at which failure would occur in practice. He also acknowledged that the deviation could be reduced if CSA specifications were modified in the following ways: (1) the nominal bar area was used instead of the actual bar area in calculations of stress and (2) the maximum rate of loading was reduced. Allen concluded, however, that the current control methods for testing were adequate.

Mirza and MacGregor (1979) published a study that addressed the variability of mechanical properties of reinforcing steel (Mirza \& Macgregor, 1979). In this study, variations in yield and tensile strength and in modulus of elasticity were examined. These variations were believed to be caused by varying rolling practices and quality control measures used by different manufacturers, as well as possible variation in cross-sectional area, steel strength, and rate of loading. The study was based on a sample that included 3,947 bars taken from 13 sources, some published and some unpublished. Mirza and MacGregor (1979) found that the beta distribution could be used to represent the probability distributions for both yield and tensile strength. They also found that the data they used for each grade of steel could be closely represented with a normal distribution between about 5 th and 95th percentile. At the lower end of the tail, their data dropped well below the normal distribution line for all grades evaluated. Conversely, data at the upper tail curved above the normal distribution line for Grade 40 yield strength and below the normal distribution line for Grade 60 yield strength and tensile strength.

Joshi and Ranganathan (1988) collected data on yield strength and modulus of elasticity of steel bars from different rolling mills and building sites and performed a statistical analysis of the same. They calculated the total variation of strength of steel bars and found that normal and log-normal distributions fit the data.

Bournonville, Dahnke and Darwin (2004), evaluated the variability of the mechanical properties and weight of steel reinforcing bars produced in the United States and Canada under various ASTM standards. They conducted a statistical analysis on data from 29 mills and developed expressions to represent the probability distributions functions for yield and tensile strength, elongation and percentage of nominal weight. Trends in the data are evaluated based on grade, bar size and production mill. Both normal and Beta distribution functions for yield and tensile strength depending on bar size, grade and steel type, as well as for all bars for each grade and steel type. They gave some percentage for the steel heats that failed to meet minimum ASTM standards (Bournonville, Dahnke, \& Darwin, 2004).

Tat (1991), investigated the distribution of mechanical properties for NZS 3402 Grade 300 and micro alloyed grade 340 reinforcing steel bars. For the both grade of steel distribution of lower yield strength, tensile strength, elongation at fracture, Luder strain at yield point, strain hardening parameters $\mathrm{n}$ and $\mathrm{k}$, and the three parameters measuring strain aging index were determined. Multiple linear regression techniques were used to investigate relationship between the determined mechanical properties and the steel chemical composition. The regression analysis yielded simple linear equations which can be used to predict the mechanical properties of bars from production on variation in chemical composition (Tat, June 1991).

Rai (2012), evaluated the properties of steel reinforcing bars for seismic design and found that for dependable flexure behavior, yield strength and ultimate tensile strength values should be lie in a narrow band around value used in the member design. If these values are greater than the specified value, it may cause brittle shear failure instead of more ductile and desirable flexure mode of failure. They conducted test on thirty beams to either failure or to the maximum displacement available with 
the actuator. They studied flexural strength, shear strength, failure mode and cracking pattern in the beams (Rai, Jain, \& Chakrabarti, 2012).

Taher (2013), presented the conference paper addressed variability in yield strength and elongation of reinforcing steel bars. In that study, they conducted statistical analysis on the collected yield strength and elongation data of reinforcing steel bars obtained from different sources and tested at university laboratory. Probability distribution functions were developed to represent the yield strength and elongation tested data for each bar size, source, grade, as well as for combined bars (Taher, Abmdas, \& Elmazoghi, 2013).

Information regarding controlled cooling process is described in Appendix B of NS:191. The process of reinforcing steel is usually through one or combination of processes which may include hot rolling after micro-alloying, hot rolling followed by controlled cooling (TMT process) and hot rolling followed by cold work.Heat treatment is a thermal process undergone by the steel in the solid state. The most common practice is finishing online heat treatment while rolling, commonly known as thermomechanical treatment (TMT) process. After leaving the last stand of the rolling mill, the bar are quenched (rapidly cooled) in water from a final rolling temperature of about $9500 \mathrm{C}$. The quenching is partial, only until a surface layer has been formed from austenite (a steel phase stable only at very high temperature) to martensite (stable at temperature below 3500C). This controlled quenching is achieved in one or more online water cooling devices through which the steel passes at a very high speed before reaching the cooling bed.

Because the quenching is only partial, a part of the original heat remains in the core of the steel and, on the cooling bed, this heat migrates towards the surface. This result in an automatic self-tempering process where the surface layer of martensite is tempered; this 'tempering temperature' (or equalizing temperature) refers to maximum temperature attained by the bar surface after quenching. Tempering enables a partial diffusion of carbon out of the extremely brittle but strong martensite, thus relieving the inherent stresses locked in during the sudden quenching of the red hot steel in cold water. The resulting tempered- martensite shows improved deformability compared to the as-quenched martensite. The core of the heat treated reinforced bars/wires consist of ferrite and perlite- more ductile but less strong than the martensite. Computerized process control is used to dynamically adjust the many rapidly changing parameters depending on the chemical composition of the steel, the desired grade and size of the reinforcing bar/wire etc. For the larger diameters, small addition of micro-alloys is usual (NS:191-2046, 2069).

\section{Methodology}

The calculation and testing of mechanical properties of reinforcement bars involve a set of procedure starting from sample collection to test results analysis as outlined in the following flowchart Figure1. There are many different types of industries within metal sector in Nepal that includes both ferrous and non-ferrous metal industries. However, for the present study, mainly hot rolling mills has been considered as they are dominant in Nepal. The rolling mills use imported continuous cast billets to manufacture various diameters and length of deformed iron bars to be used for reinforcing concrete structure. 


\subsection{Sample collection}

In the present study, mainly hot rolling mills has been considered as they are dominant in Nepal. The common size of reinforcement bar being manufactured are $8 \mathrm{~mm}, 10 \mathrm{~mm}, 12 \mathrm{~mm}, 16 \mathrm{~mm}, 20 \mathrm{~mm}$, $25 \mathrm{~mm}, 28 \mathrm{~mm}$ and $32 \mathrm{~mm}$ nominal diameter. This study covers the TMT bar of Fe500 and Fe500D grades. The representative samples are selected which are available at NBSM mechanical testing sample reference room. No samples were collected from industry premises or market. The study covers samples of twenty two brands of nineteen industries granted with NS mark for their products.

These reinforced bars are from FY 2073/74 and FY 2074/75. Samples are segregated from reference room as according to Grade $\mathrm{Fe} 500$ and $\mathrm{Fe} 500 \mathrm{D}$, brand name, and diameter of reinforced bars. Total 745 number of samples of 22 different brand was collected. Among them, 19 brand were Fe 500 TMT bars and 3 brands were Fe 500D grade TMT bars. The diameter of the collected samples were $8 \mathrm{~mm}, 10 \mathrm{~mm}$, $12 \mathrm{~mm}, 16 \mathrm{~mm}, 20 \mathrm{~mm}, 25 \mathrm{~mm}, 28 \mathrm{~mm}$, and $32 \mathrm{~mm}$. To provide confidentiality to all manufacturers brand collected for this work, a short code name is assigned to all brand. The sample size of each grade of reinforcing steel are listed in Table 1.

Table1 Sample size of deformed bars used for mechanical test

\begin{tabular}{|c|c|c|c|c|c|c|c|c|c|}
\hline \multirow{2}{*}{ Grade } & \multicolumn{8}{|c|}{ Diameter of bar, mm } & \multirow{2}{*}{$\begin{array}{c}\text { Total } \\
\text { nos. of } \\
\text { samples }\end{array}$} \\
\hline & 8 & 10 & 12 & 16 & 20 & 25 & 28 & 32 & \\
\hline $\mathrm{Fe} 500$ & 95 & 95 & 95 & 95 & 95 & 70 & 35 & 30 & 610 \\
\hline Fe500D & 15 & 15 & 15 & 15 & 15 & 15 & 15 & 10 & 135 \\
\hline
\end{tabular}

\subsection{Sample preparation}

For mechanical and physical testing of collected samples of different grades and brands, the following test method and product standard were followed:

1. Metallic Materials- Tensile Testing at Ambient Temperature (IS 1608:2005, ISO 6892:1998)

2. Steel for the Reinforcement and Pre-stressing of Concrete- Test methods Part-1, ISO 15630-1)

3. Metallic Materials- Tensile Testing, Part 1: Method of test at ambient temperature, BS EN 10002-1:2001)

4. Deformed Steel Bars and Wires for Concrete Reinforcement (NS 191-2046)

5. High Strength Deformed Steel Bars and Wires for Concrete Reinforcement- Specification (IS $1786: 2008)$ 
With the help of mentioned test method and product standard, sample was prepared for tensile test. At first, mass and length of sample were noted and with the help of this effective cross-sectional area and original gauge length were calculated. Samples were prepared for re-bend test also.

\subsection{Mechanical testing of samples}

Following mechanical test are conducted at NBSM physical testing laboratory. Total 435 numbers of TMT bars are tested for tensile properties (mass per meter run, yield strength, ultimate tensile strength, percentage elongation, UTS/YS ratio) and 310 numbers of samples are used for testing bond value, bend test and re-bend test.

To conduct tensile testing of the samples two type of universal testing machines (UTM) were used. One UTM is of $600 \mathrm{kN}$ capacity, Tinus Olsen, USA made, Figure 2 in which there is provision for selection of load range $60 \mathrm{kN}, 300 \mathrm{kN}$ and $600 \mathrm{kN}$. AnotherUTM Machine is HEICO, shown in Figure 2, made in India which is of $1000 \mathrm{kN}$ capacity with software based. During the thesis work it is tried to test most of samples in HEICO but due to the work load of regular sample of NBSM it was not possible to conclude all samples, so some samples are also tested in Tinus Olsen UTM machine. Also for $8 \mathrm{~mm}$ and $10 \mathrm{~mm}$ size the precise result can be obtained from $60 \mathrm{kN}$ range than that of $1000 \mathrm{kN}$. Also for gripping there is problem in $1000 \mathrm{kN}$ machine for smaller size and it arises slip problem.
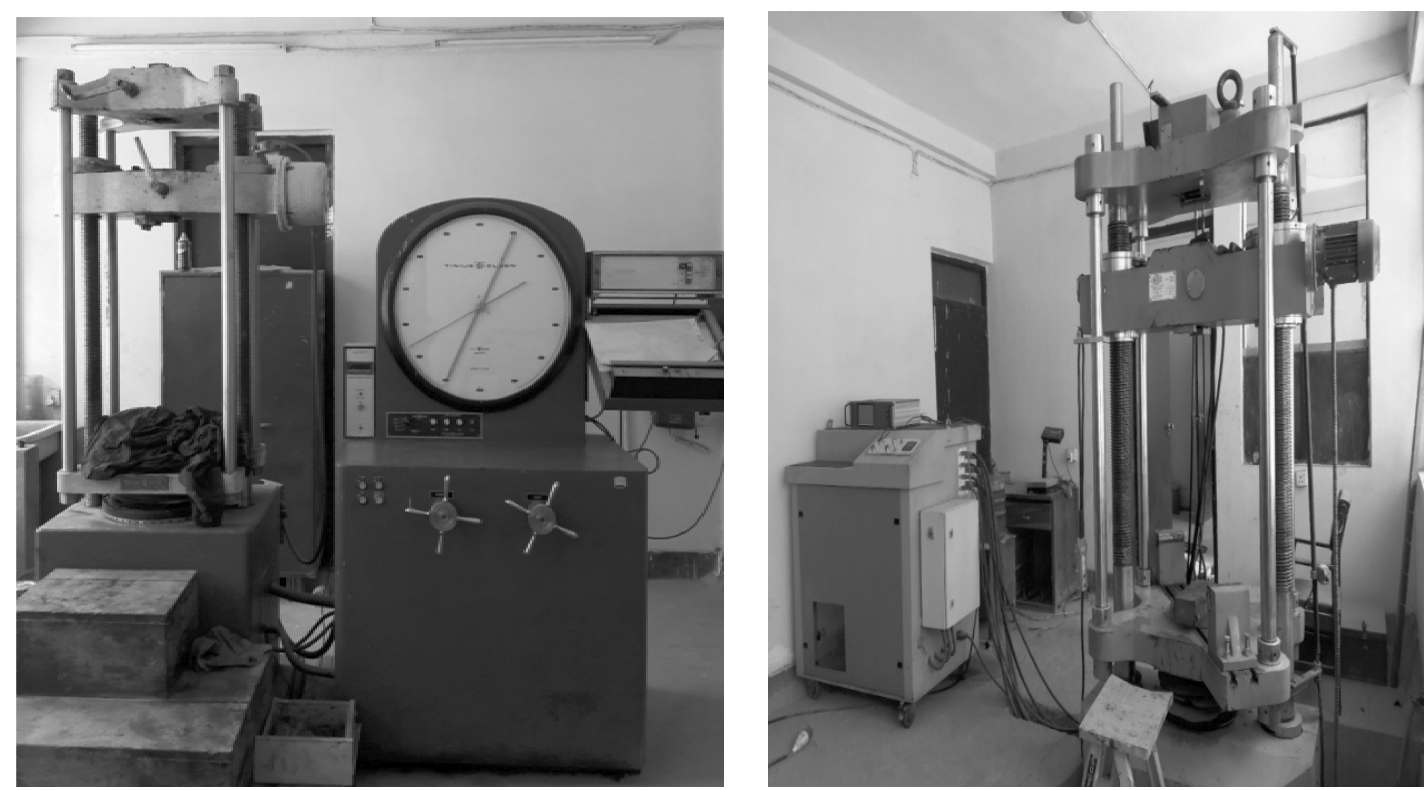

Fig 2 UTM machines at NBSM Mechanical testing lab

\subsection{Statistical analysis of test results}

The data obtained from test results are statistically analyzed to evaluate the variability in the mechanical properties of TMT bars. For the tested mechanical properties, the following parameters are evaluated for each bar size, and grade at confidence level at 95\%: mean, standard deviation, coefficient of variation, minimum, maximum, skewness.

\section{Result and Discussion}

Deformed steel bars conforming to the Nepal Standards NS: 191-2046 (Rev.2069) has been commercially available and widely used over the past years. TMT bar of grade Fe500 is mostly manufactured by the steel industries. However, TMT bar of grade Fe500D is improved form of Fe500 grade. Fe500D grade of TMT bar has different chemical composition than Fe500TMT bars. Fe500D grade TMT bars have lower Carbon, Sulphur, and Phosphorous percent than Fe 500 grade. Although, 
the minimum Yield stress value is same as Fe500 grade, it has high ductility, higher value of ultimate tensile stress and one additional parameter total elongation at maximum force is added for this grade.

The mechanical test results are analyzed on three basis: Comparing test results with minimum value specified in NS:191 standard, analyzing test results on bar size and grade, and finally test results are comparing among the rolling mills.

\subsection{Comparing data with minimum NS standard}

The summary of comparing of mechanical test results with minimum NS standards are shown in Table 2 and Table 3 for Fe500 and Fe500DTMT bars respectively. In comparing tested results data with the minimum standards set forth by NS, the following observations are made:

Table 2 Comparing tested data with minimum NS standards for Fe500TMT bars

\begin{tabular}{|c|c|c|c|c|c|c|c|c|}
\hline \multirow{2}{*}{ Min. Value for Fe500 } & \multicolumn{8}{|c|}{ Diameter of Bars, mm } \\
\hline & 8 & 10 & 12 & 16 & 20 & 25 & 28 & 32 \\
\hline Yield Strength, MPa & 506.0 & 517.2 & 519.5 & 517.4 & 519.0 & 506.9 & 521.2 & 512.3 \\
\hline NS: 191 & \multicolumn{8}{|c|}{ Min. 500.0MPa for all bar size } \\
\hline Tensile Strength, MPa & 601.6 & 591.3 & 584.6 & 599.4 & 624.0 & 625.2 & 637.0 & 632.3 \\
\hline NS: 191 & \multicolumn{8}{|c|}{ Min. 8\% more than actual Y.S. but not less than $545.0 \mathrm{MPa}$} \\
\hline Percentage Elongation, \% & 20.8 & 20.0 & 17.8 & 18.8 & 18.7 & 18.9 & 17.9 & 18.8 \\
\hline NS: 191 & \multicolumn{8}{|c|}{ Min. $12.0 \%$} \\
\hline Bond Value, mm & 1.06 & 1.17 & 1.78 & 1.95 & 3.42 & 4.25 & 4.81 & 5.53 \\
\hline NS: 191 & 0.96 & 1.2 & 1.8 & 2.4 & 3.4 & 4.25 & 4.76 & 5.44 \\
\hline Mass per meter Run, $\mathrm{Kg} / \mathrm{m}$ & 0.379 & 0.592 & 0.864 & 1.519 & 2.409 & 3.749 & 4.682 & 6.177 \\
\hline NS: 191 & 0.363 & 0.568 & 0.835 & 1.485 & 2.371 & 3.696 & 4.637 & 6.058 \\
\hline
\end{tabular}

A value of yield strength was tested for 435 numbers of individual samples for this study. All the tested samples comply with the minimum NS standard requirement for their respective grade. The minimum yield strength value is $500 \mathrm{MPa}$ for both Fe500 and Fe500DTMT bar. Total 145 sets of samples were tested at NBSM mechanical testing laboratory. Each set represents the mean value of three samples. In this case, all the tested samples comply with the minimum value specified in product standard. The minimum value for Fe500TMT bar is $8 \%$ more than actual yield stress but not less than 545.0 MPa. For Fe500D grade TMT bars the minimum value is $10 \%$ more than actual yield stress but not less than 565.0 MPa. From the test results, it was observed that the test results are well above the minimum requirement. For Fe500TMT bars the minimum value is $12.0 \%$ and that for Fe500D is $16.0 \%$. The minimum value of percentage elongation for Fe500 grade TMT bars have lower value than that of Fe500D grade TMT bars. The reason behind this is superior chemical composition than that of Fe500 grade TMT bars raw material. Mass per meter run is calculated for 435 numbers of samples from grade Fe500 and Fe500D. All the tested samples comply with minimum value specified in product standard for their respective bar size, and grade. Since all the tested samples are treated as individual, the given lower tolerances for respective sizes were taken in consideration. All the tested samples were found within the tolerance limit specified in product standard. 
Table 3 Comparing tested data with minimum NS standards for Fe500DTMT bars

\begin{tabular}{|c|c|c|c|c|c|c|c|c|}
\hline \multirow[t]{2}{*}{ Min. Value for Fe500D } & \multicolumn{8}{|c|}{ Diameter of bars, mm } \\
\hline & 8 & 10 & 12 & 16 & 20 & 25 & 28 & 32 \\
\hline Yield Strength, MPa & 539.0 & 512.5 & 547.1 & 556.0 & 520.9 & 556.6 & 530.9 & 551.0 \\
\hline NS: 191 & \multicolumn{8}{|c|}{ Min. 500.0 MPa for all bar size } \\
\hline Tensile Strength, MPa & 623.9 & 616.5 & 661.0 & 670.9 & 644.8 & 671.2 & 659.1 & 668.1 \\
\hline NS: 191 & \multicolumn{8}{|c|}{ Min. $10 \%$ more than actual Y.S. but not less than $565.0 \mathrm{MPa}$} \\
\hline Percentage Elongation, \% & 21.7 & 22.7 & 21.1 & 19.6 & 20.3 & 19.4 & 19.8 & 21.3 \\
\hline NS: 191 & \multicolumn{8}{|c|}{ Min. 16.0\% } \\
\hline Bond Value, mm & 1.06 & 1.78 & 2.60 & 2.80 & 4.62 & 4.78 & 5.15 & 6.58 \\
\hline NS: 191 & 0.96 & 1.2 & 1.8 & 2.4 & 3.4 & 4.25 & 4.76 & 5.44 \\
\hline Total elongation at Max. Force & 5.3 & 5.7 & 9.8 & 6.8 & 7.3 & 7.3 & 7.3 & 9.3 \\
\hline NS: 191 & \multicolumn{8}{|c|}{ Min. 5.0\% } \\
\hline Mass per meter Run, $\mathrm{Kg} / \mathrm{m}$ & 0.381 & 0.598 & 0.860 & 1.550 & 2.409 & 3.754 & 4.760 & 6.230 \\
\hline NS: 191 & 0.363 & 0.568 & 0.835 & 1.485 & 2.371 & 3.696 & 4.637 & 6.058 \\
\hline
\end{tabular}

Total 69 numbers of samples of Fe500D grade were tested for this mechanical properties. All the tested samples were comply with minimum value specified in product standard. The minimum value specified for Fe 500D grade is 5.0\%. Bend and re-bend test are qualitative test. All the tested samples of both grade Fe500 and Fe500D grade comply with the NS requirements. Total 145 samples of different size and grades are tested. There is no transverse crack were found in the bent portion of the sample tested for bend test. There is no fracture were found in the bent portion for samples tested for re-bend test. The percentage elongation value is also more than minimum NS requirements satisfy the qualitative test results.

\subsection{Data trends: bar size and grade}

There is significant trend observed in the data for yield strength of Fe500TMT bars. Here, the average yield strength first decreases from $573.9 \mathrm{MPa}$ for $8 \mathrm{~mm}$ bars to $544.8 \mathrm{MPa}$ for $16 \mathrm{~mm}$ bars and then increases steadily with bar sizes. The lowest average value of yield strength were found for $32 \mathrm{~mm}$ bars. Overall, the average yield strength is $554.4 \mathrm{MPa}$ for all Fe 500 TMT bars. The data trends for $8 \mathrm{~mm}$ to $32 \mathrm{~mm}$ bar size of grade Fe500TMT bars shown in Figure 3. For bar of grade Fe500D, the average yield strength were 565.2 MPa. No any significant trend were observed for Fe500D grade TMT bars. Figure 4 shows the data trends for Fe500DTMT bars. The lowest average yield strength value for Fe500D grade was found for $10 \mathrm{~mm}$ bar size and highest average yield strength for $16 \mathrm{~mm}$ bar size. 


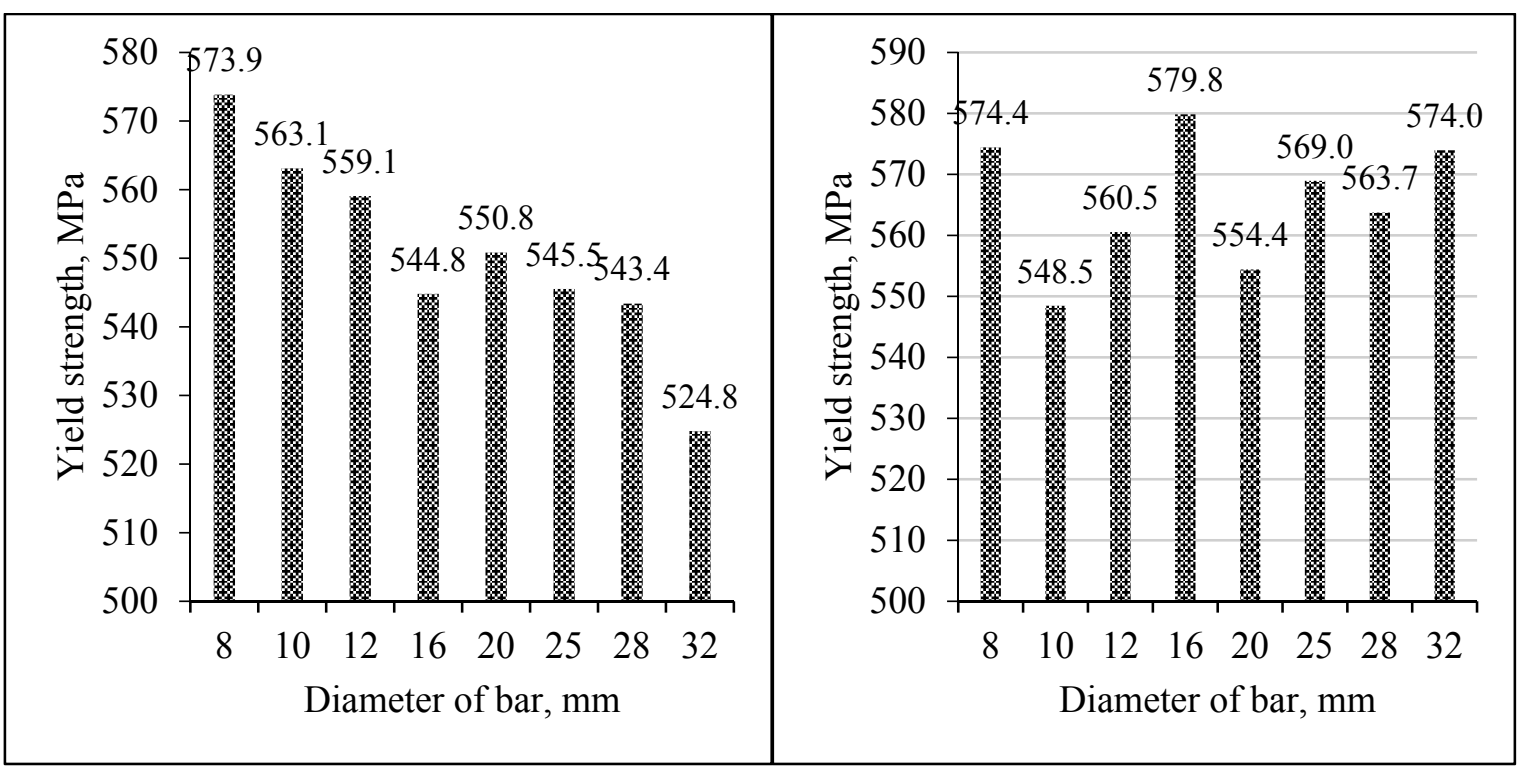

Fig 3 Avg. Yield strength Fe500

Fig 4 Avg. Yield strength Fe500D

Unlike yield strength, the tensile strength of Fe500TMT bars generally decreases with an increase in bar diameter $688.0 \mathrm{MPa}$ to $650.6 \mathrm{MPa}$, from $8 \mathrm{~mm}$ to $16 \mathrm{~mm}$. From $20 \mathrm{~mm}$ to $28 \mathrm{~mm}$ bars show the average tensile strength value almost constant. For $32 \mathrm{~mm}$ bar size the lowest average tensile strength were found as shown in Figure 5. The mean value of tensile strength for Fe500 grade was found 663.4 $\mathrm{MPa}$ with minimum value 584.6 $\mathrm{MPa}$ and maximum value $730.3 \mathrm{MPa}$.

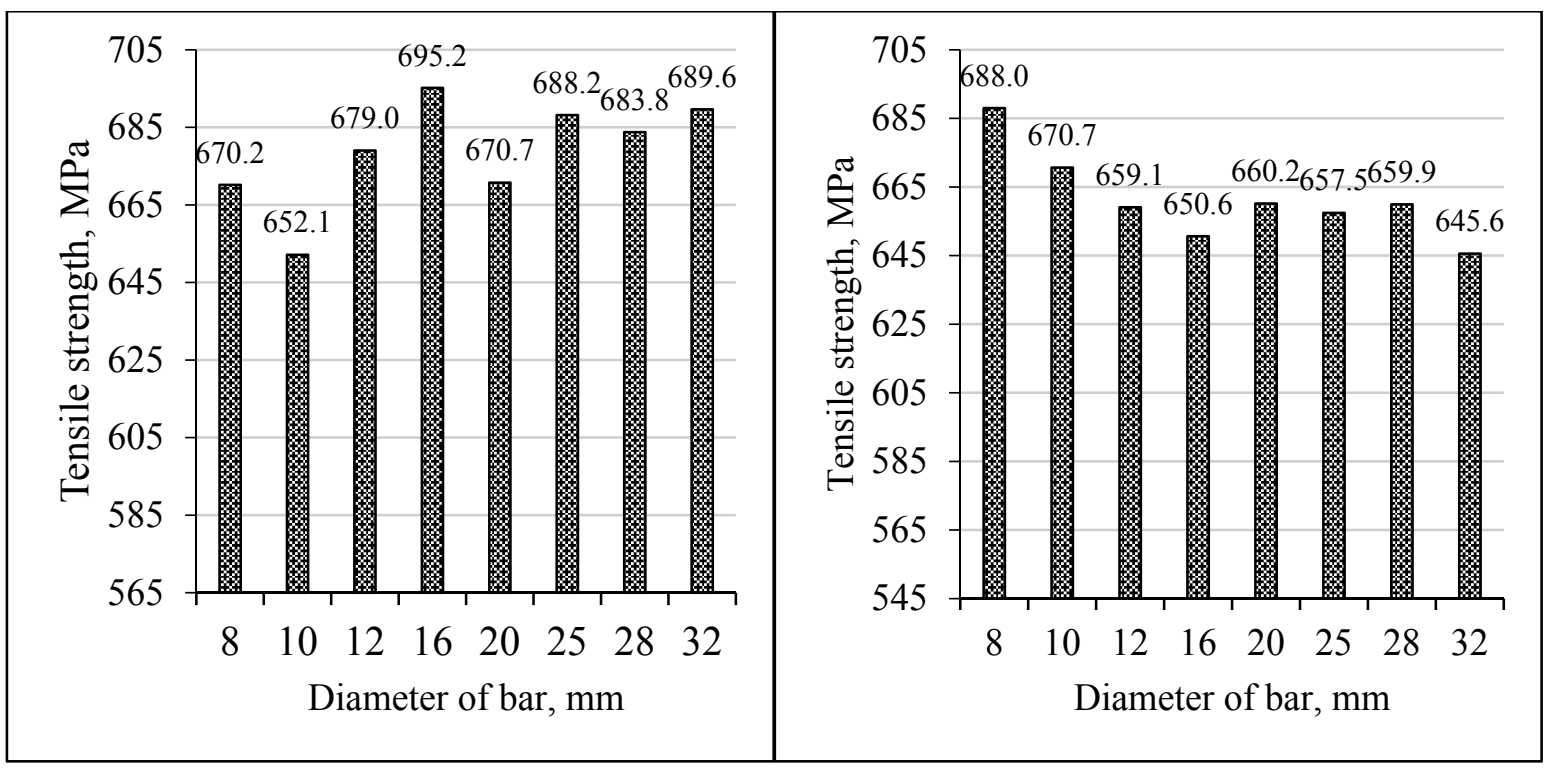

Fig 5 Avg. Tensile strength Fe500

Fig 6 Avg. Tensile strength Fe500D

The data trends for average tensile strength for Fe500D samples are shown in Figure 6. Range in tensile strength for Fe500D samples are 616.5 MPa to 716.9 MPa. There is more variation in tensile strength found for Fe500D grade than Fe500TMT bars samples.

The average percentage elongation for Fe500TMT bars were found from the tested sample is $22.0 \%$. The maximum value of percentage elongation of tested samples was found $26.7 \%$ and minimum value 17.8\%. Figure 7 show the data trend for both grade Fe500 and Fe500DTMT bar. From Figure 7 it shows that the percentage elongation value for lower diameter have more than that for higher diameter.

For Fe500D grade TMT bars, the mean value of percentage elongation found from the tested samples was $22.0 \%$, with maximum value $25.0 \%$ and minimum Value $19.4 \%$. 


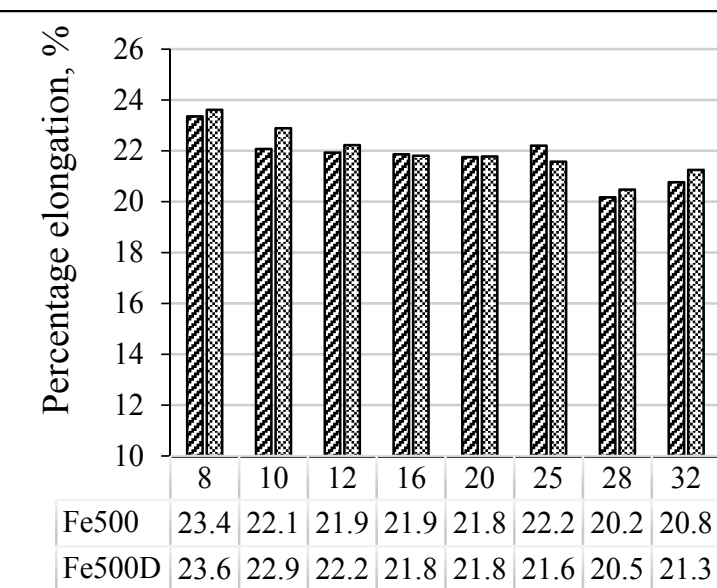

Diameter of bar, $\mathrm{mm}$

๑Fe500 $⿴ 囗 十 0500 \mathrm{D}$

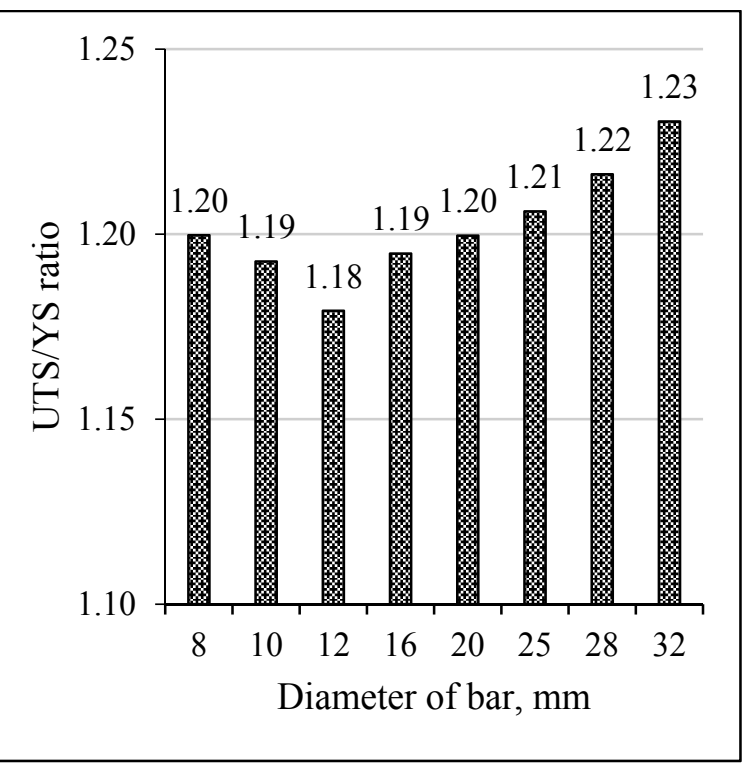

Fig 8 Avg. UTS/YS ratio Fe 500

Fig 7 Avg. Percentage elongation

The average value of UTS/YS ratio for all the tested samples of both grade Fe500 and Fe500DTMT bars were found 1.2. There is a significant trend observed in Figure 8 for UTS/YS ratio of grade Fe500 bars. Here the average UTS/YS ratio first decreases from 1.20 for $8 \mathrm{~mm}$ bars to 1.18 for $12 \mathrm{~mm}$ and then increases steadily with bar size to a maximum average UTS/YS ratio 1.23 for $32 \mathrm{~mm}$ bars. For Fe 500D grade not such trend is observed. The minimum average UTS/YS ratio was observed for $8 \mathrm{~mm}$ bars. Except $10 \mathrm{~mm}$ bars, all other sizes have average UTS/YS ratio above 1.20. The maximum average UTS/YS ratio values are observed for 1.24 for $28 \mathrm{~mm}$ bars. Since the tested values of UTS/YS ratio for both grades are above 1.150 which is good sign for material properties. The Figure 8 show the data trend of average value of UTS/YS ratio of Fe500TMT bars.

\subsection{Data trends: Rolling mills}

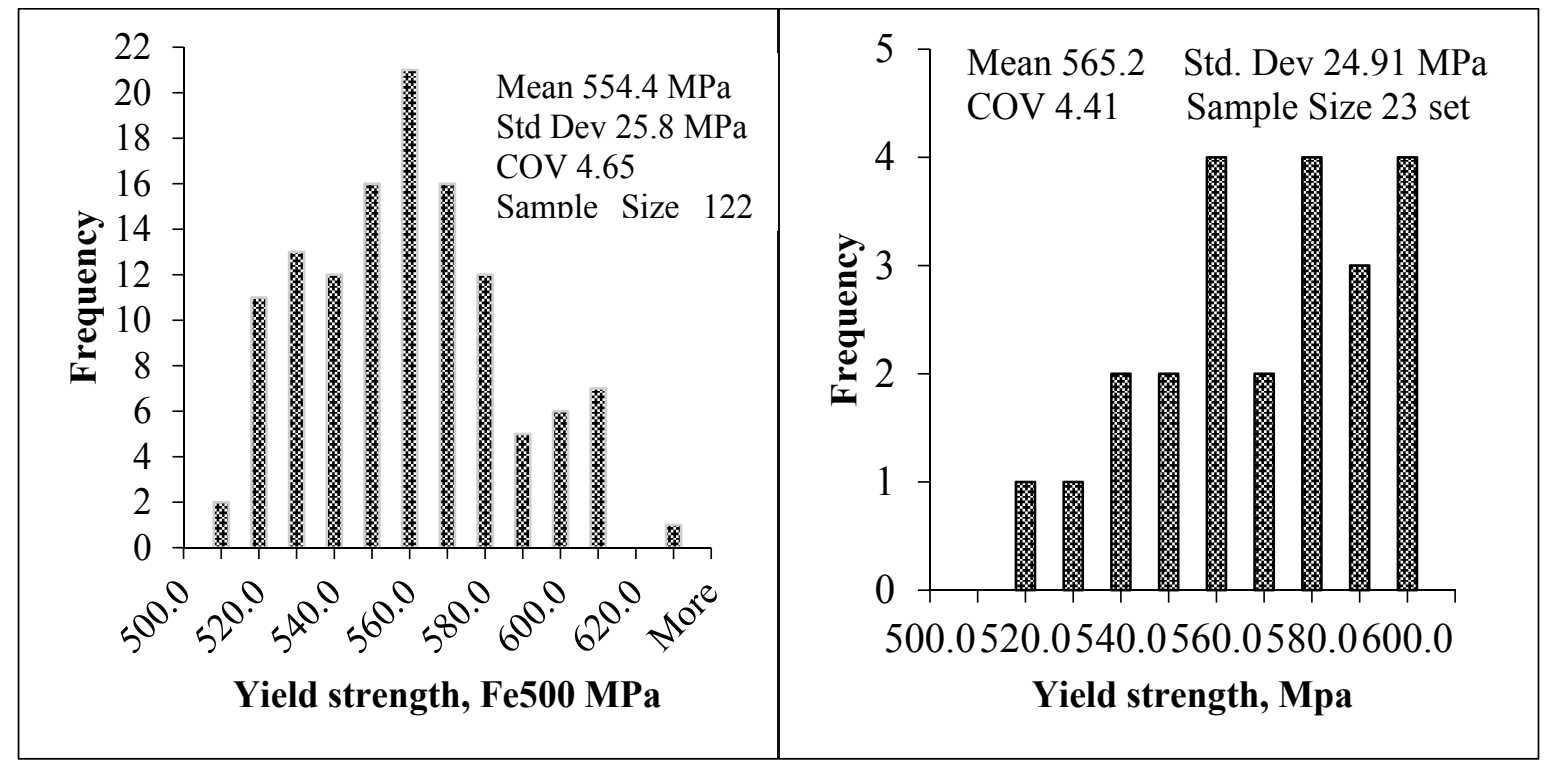

Fig 9 Distribution of yield strength

Histogram of frequency distributions of yield strength of grade Fe500TMT bars for different 122 sets of data is shown in Figure 9. As can be seen from the figure, the mean yield strength for all the tested samples at NBSM mechanical testing laboratory is $554.4 \mathrm{MPa}$. From Figure 9 it is evident data 22 sets of yield stress value obtained are $560 \mathrm{MPa}, 16$ sets of yield stress results obtained are $550 \mathrm{MPa}$ and 570 MPaeach. Histogram of frequency distributions of yield strength of grade Fe500DTMT bars for jacem, Vol 6, 2021 
different 23 sets of data is shown in Figure 9. As can be seen from the figure, the mean yield strength for all the tested samples at NBSM mechanical testing laboratory is $565.2 \mathrm{MPa}$. From Figure 9 it is evident data among the 23 sets of samples the frequency of average yield stress value for $560 \mathrm{MPa}, 580$ MPa and $600 \mathrm{MPa} 4$ times for each. Similarly, the frequency of yield stress value obtained for 2 times each for $540 \mathrm{MPa}, 550 \mathrm{MPa}$ and $570 \mathrm{MPa}$.

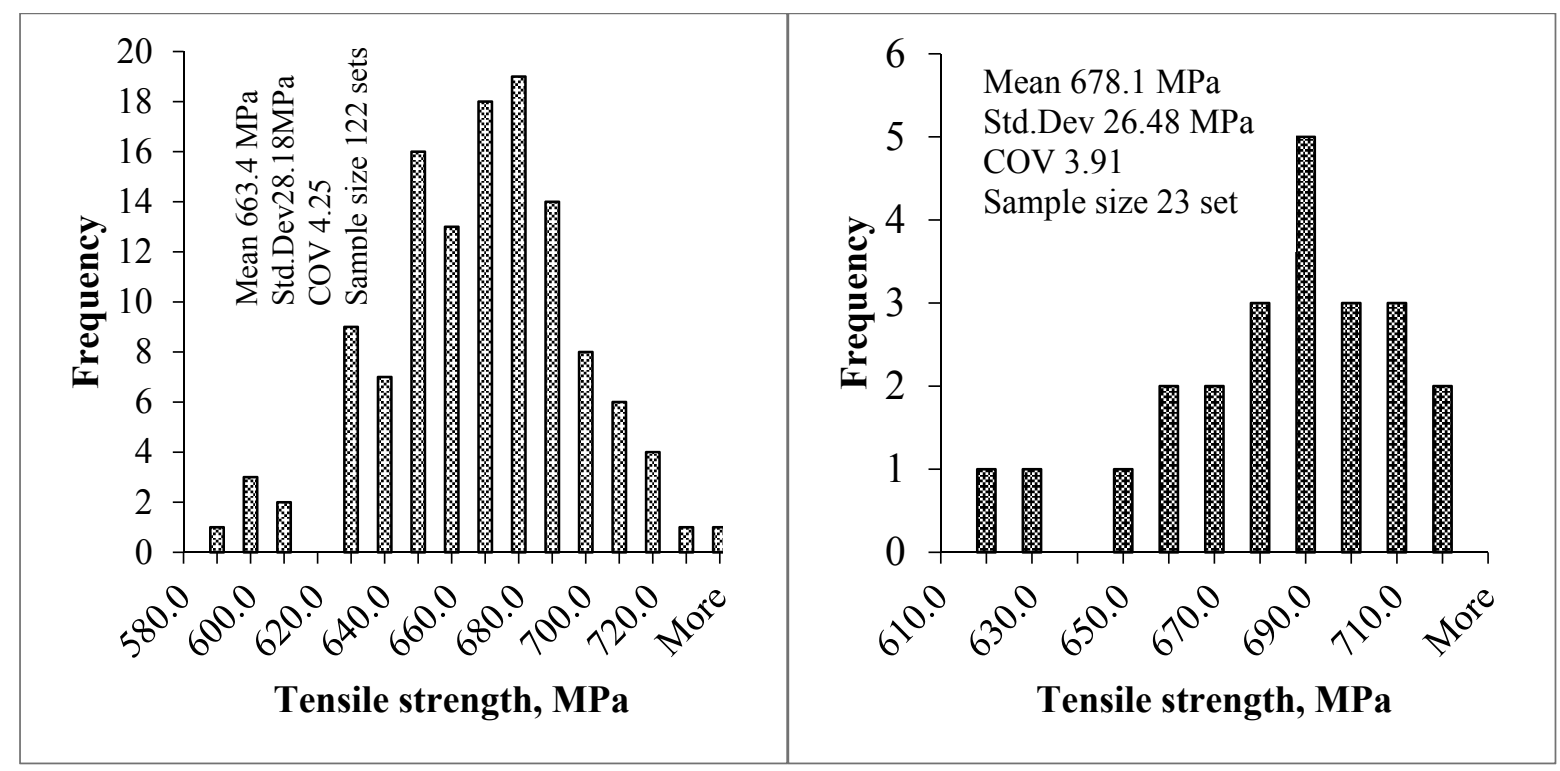

Figure 10 Distribution of tensile strength

Distributions of tensile strength of grade Fe500TMT bars for different sets of data is shown in Figure 10. As can be seen from the figure, the mean tensile strength for all the tested samples at NBSM mechanical testing laboratory is $663.4 \mathrm{MPa}$. From Figure 10 it is evident data 20 sets of tensile strength value obtained are $680 \mathrm{MPa}, 18$ sets of tensile strength results obtained are $670 \mathrm{MPa}$ and 16 sets of tensile strength results obtained are 650 MPaeach. Histogram of frequency distributions of tensile strength of grade Fe500DTMT bars for different 23 sets of data is shown in Figure 10. As can be seen from the figure, the mean tensile strength for all the tested samples at NBSM mechanical testing laboratory is $678.1 \mathrm{MPa}$. From Figure 10 it is evident data among the 23 sets of samples the frequency of average tensile strength value for $680 \mathrm{MPa}, 700 \mathrm{MPa}$ and $710 \mathrm{MPa} 3$ times for each. Similarly, the frequency of tensile strength value obtained for 2 times each for $660 \mathrm{MPa}, 670 \mathrm{MPa}$ and $720 \mathrm{MPa}$. Among the tested samples $690 \mathrm{MPa}$ tensile strength value was found for 5 times.

Histogram for frequency distributions of average percentage elongation of grade Fe500TMT bars for different 122 sets of data is shown in Figure 11. As can be seen from the figure, the mean percentage elongation for all the tested samples is $22.0 \%$. From Figure 11 it is evident data among the 122 sets of samples the frequency of average percentage elongation value for $21.0 \%$ and $21.5 \%$ are 14 times for each. Similarly, the frequency of percentage elongation value obtained for 13 times each for $23.0 \%$ and $25.0 \%$. Among the tested samples $22.0 \%$ percentage elongation value was found for 17 sets of samples. Histogram for frequency distributions of average percentage elongation of grade Fe500DTMT bars for different 23 sets of data is shown in Figure 11. As can be seen from the figure, the mean percentage elongation for all the tested samples is $22.0 \%$. From Figure 11 it is evident data among the 23 sets of samples the frequency of average percentage elongation value of $23.0 \%$ found for 8 sets of samples. Similarly, the frequency of percentage elongation value obtained for 6 sets of samples was $22.0 \% .2$ times each for $21.0 \%$ and $24.0 \%$ and $25.0 \%$. 20.0\% percentage elongation for 3 sets. 


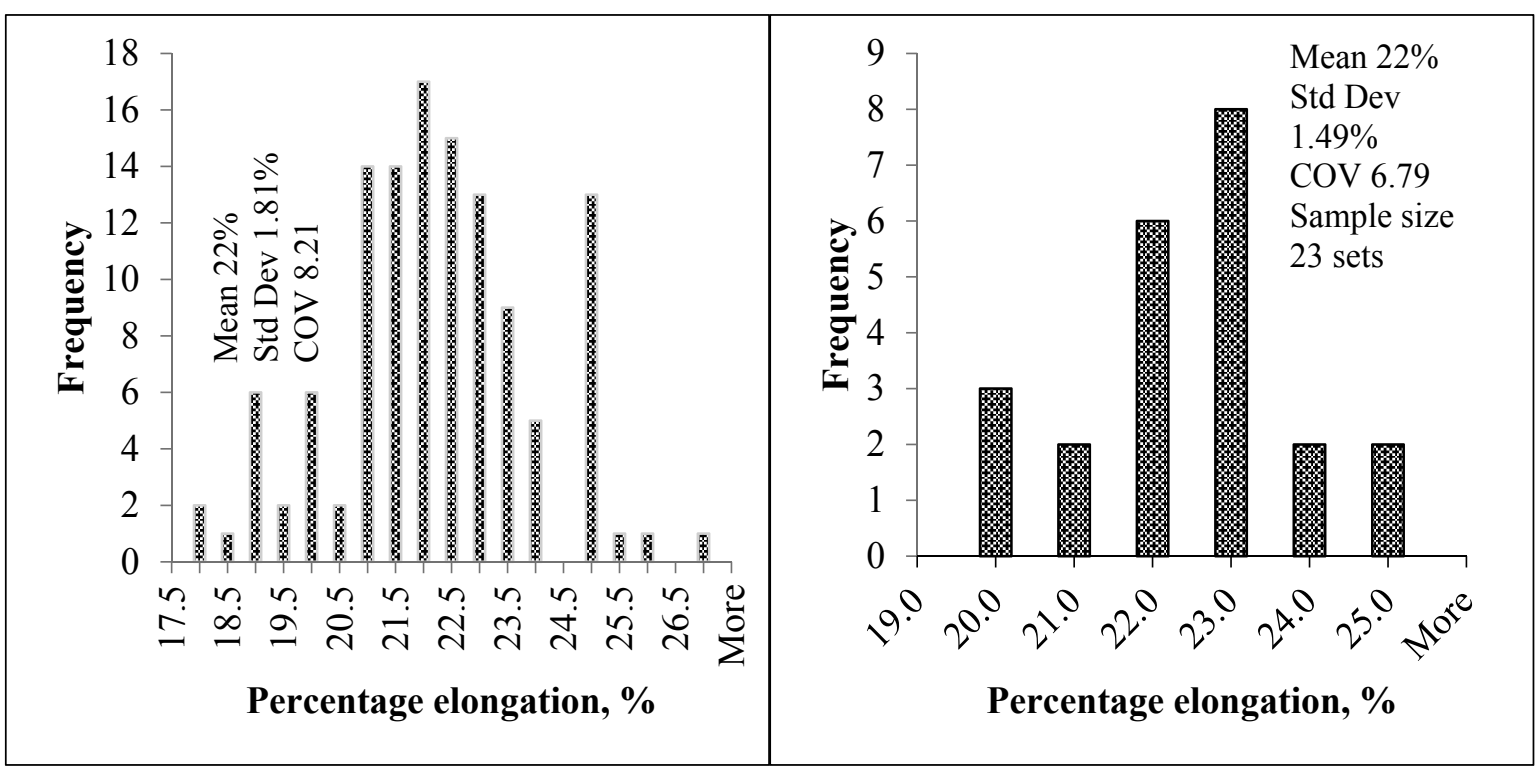

Fig 11 Distribution of percentage elongation

\section{Conclusions}

Based on these results and discussions, the following conclusions are made:

- Yield strength, tensile strength, percentage elongation, mass per meter run, total elongation at maximum force, bend test, re-bend test of all the tested samples of grade Fe500 and Fe500DTMT bars comply with minimum requirement specified in product standard NS-191. The mean yield strength of Fe500TMT bars were found $554.36 \mathrm{MPa}$ with minimum value $505.98 \mathrm{MPa}$ and maximum value $627.05 \mathrm{MPa}$. The mean value of tensile strength of Fe500TMT bars samples were found $663.43 \mathrm{MPa}$ with minimum value 584.56 $\mathrm{MPa}$ and maximum value $730.28 \mathrm{MPa}$. The mean value of percentage elongation for Fe500TMT bars were obtained $22.0 \%$ with minimum value $17.78 \%$ and maximum value $26.67 \%$. The mean value of UTS/YS ratio of Fe500TMT bars were found 1.198 with minimum value 1.109 and maximum value 1.256 .

- The mean value of yield strength for Fe500D grade bars were calculated $565.18 \mathrm{MPa}$ with minimum value $512.51 \mathrm{MPa}$ and maximum value $599.72 \mathrm{MPa}$. The mean value of tensile strength of Fe500DTMT bars samples were found $678.12 \mathrm{MPa}$ with minimum value 616.46 $\mathrm{MPa}$ and maximum value $716.87 \mathrm{MPa}$. The mean value of percentage elongation of Fe500D samples were calculated $21.98 \%$ with minimum value $19.44 \%$ and maximum value $25 \%$. The mean value of total elongation at maximum force were calculate from tested samples of Fe500D were $8.27 \%$ with minimum value $5.34 \%$ and maximum value $12.09 \%$.

- The COV for average yield strength of Fe500 were obtained 4.65 and standard deviation 25.80 $\mathrm{MPa}$. The COV for average tensile strength of Fe500 were calculated 4.25 and standard deviation were $28.18 \mathrm{MPa}$. The COV of the percentage elongation were found 8.21 and standard deviation $1.18 \%$. The value of COVfor UTS/YS ratio were found 2.50 and standard deviation value were calculated 0.030 .

- The COV for yield strength of Fe500D were found 4.41 and standard deviation 24.91 MPa. The COV for average tensile strength were calculated 3.91 and standard deviation were $26.48 \mathrm{MPa}$. The COV for percentage elongation were found 6.79 and standard deviation $1.49 \%$. The value of COV for UTS/YS ratio were found 2.057 and standard deviation value were calculated 0.025 . The COV for total elongation at maximum force were calculated 21.71 and standard deviation $1.8 \%$. 
- Total 122 numbers of Fe500TMT bars and 23 numbers of Fe500DTMT bars were tested by area of projection method for bond value calculation. Among the tested samples 2 (1.37\%)did not meet with the minimum NS standards for their respective bar size, and grade. The sample coded with PKS_12mm and NRS_16mm were failed to comply with minimum requirement.

\section{Acknowledgement}

Authors thankfully acknowledge the help and co-operation rendered by Nepal Bureau of Standards and Metrology for providing samples, laboratory facilities for conducting tests of reinforced bar as per NS:191-2063 and information regarding licensed industries in hot rolling mill field.

\section{References}

1. Allen, D. (1972). "Statistical Study of the Mechanical Properties of Reinforcing Bars, Building Research Note No. 85." Ottawa, Canada: Division of Building Research, National Research Council, Apr. 8 pp.

2. Bournonville, M., Dahnke, J., \& Darwin, D. (2004). "Statistical Analysis of the Mechanical Properties and Weight of Reinforcing Bars." A Report on Research Sponcored by The University of Kansas Structural Engineering and Materials Laboratory.

3. CME. (2012/13). "Census of Manufacturing Establishment."

4. GIZ/NEEP. (2012).

5. Mirza, S., \& Macgregor, J. (1979). "Variability of Mechanical Properties of Reinforcing Bars." Journal of the Structural Division, ASCE, Vol. 105, May , pp. 921-937.

6. NBC, N. (1994). Ministry of Physical Planning and Works, Government of Nepal (different volumes).

7. NS:191-2046. (2069). "Deformed Steel Bars and Wires for Concrete Reinforcement (Second ed.)". Kathmandu, Nepal: Nepal Bureau of Standards and Metrology.

8. Rai, D., Jain, S., \& Chakrabarti, I. (2012). "Evaluation of Properties of Steel Reinforcing Bars for Sesmic Design." 15 WCEE LISBAO .

9. Taher, L., Abmdas, M., \& Elmazoghi, H. (2013). "Variability in Yield Strength and Elongation of Reinforcing Steel Bars." University of Benghazi, Faculty of Engineering, Civil Eng. Department.

10. Tat, L. W. (June 1991). "Statistical Analysis of Reinforcing Steel Properties." N: University of Canterburry Christchurch, Newzealand. 